\title{
SURGICAL GOWN FABRIC; DETERMINATION OF RESISTANCE TO SURFACE WETTING OF EXISTING SURGICAL GOWN FABRIC.
}

1. Ph.D.

Associate Professor

Govt. College of Home Economics, Gulberg, Lahore.

2. Fourth Year MBBS, AMDC, Lahore.

Correspondence Address:

Farzana Kishwar

Associate Professor

Govt. College of Home Economics,

Gulberg, Lahore.

f_kishwar@yahoo.ca

Article received on: 06/04/2017

Accepted for publication:

30/06/2017

Received after proof reading:

$03 / 07 / 2017$

\section{Farzana Kishwar ${ }^{1}$, Fatima Ali ${ }^{2}$}

ABSTRACT... Objectives: 1 . To find out the affect of surface wetting of existing surgical gown fabric before and after laundering (among three groups of hospitals). 2. To compare the results of surface wetting of existing surgical gowns among three groups of hospitals. Study Design: The study has Experimental design. Period: March, 2017- June, 2017. Setting: This fabric was collected from different govt. and private hospitals under study. Materials and Methods: The surgical gown fabric was used as sample for experiments. All the experimental work was done at PCSIR Labs. Lahore. Result and Conclusion: According to the above graph figure 04 the resistance of fabric to surface wetting (spray test) was absolutely same in Group B and C. However, in Group A, the values were slightly greater than other two groups from new gown to $10^{\text {th }}$ laundering intervals and became null in further laundering, similar to group A and B. The resistance to surface wetting nullified in almost all groups after $5^{\text {th }}$ laundry and no statistical difference was observed in resistance of fabric in all groups i.e. ( $p$-value $=0.423$ ). These gowns did not match any international standard or parameter either. After repeated launderings most of the gowns were torn and became discolored. Among three groups under study group $A$ showed highest ratings in ISO-Spray test where as for weft yarns group c failed the test.

Key words: Surgical Gowns, existing surgical gowns, Spray test, Surface Wetting, Parameters.

Article Citation: Kishwar F, Ali F. Surgical gown fabric; Determination of resistance to surface wetting of existing surgical gown fabric. Professional Med J 2017;24(7):966971. DOI: $10.17957 / T P M J / 17.4105$

\section{INTRODUCTION}

The surgical gowns and scrubs play pivotal role in barrier system against the prevention of wound infection. It is the duty of health care workers to provide infection free environment for the patient undergoing surgical procedure. In the perioperative setting, prevention of contamination for both patients to be operated and personnel is a prime objective. In contamination control plans the appropriate choice and use of operating attire is an indispensable element. So, perioperative staff and operating technicians need to be wellinformed about the basic considerations in choosing and using surgical robes effectively in the operating preparation settings. Body fluids transmit bacteria, viruses and other particles. Operating robes should give a safe and effective protection to patients and medical personnel for the duration of their work. Patients are always vulnerable to infection from endogenous microorganisms and exogenous microorganisms as well. Similarly medical personnel are at threat for infection from numerous blood borne microorganisms from patients' blood and body fluids. It is necessary for the patients' protection that operating gowns should also offer an effective defensive block against the transmission of pathogens, tiny particles, and body fluids in order to decrease strike-through and the prospective for health care workers infection. A good surgical gown should have some characteristics. ${ }^{19}$

At present, the biggest professional hazard faced by medical personnel is interaction with infectious fluids in usual patient care. This acquaintance to infections raises the possibility for severe contamination and might be fatal. ${ }^{12}$

The medical staff working in surgery and gynecology departments is more at risk than those working in medicine or other departments. 
At present, surgical gowns and drapes are being used to defend healthcare professionals as well as the patients from microbes, transmitted by the medical staff and patient by themselves ${ }^{17,23}$ Rise in the occurrence of resistant microorganisms that can be easily transferred is alarming. ${ }^{1}$ These problems are directing to the fabrication of advanced new products in the fabric manufacturing units. The surgical apparels and linen made of cotton fabric lose their barrier efficacy when damp, the assessment and improvement in materials with appropriate barrier efficacy for consumption in operation theatre, is still under investigation. Fabrics have the ability to be proper barrier still they need to stop the transference of microorganisms and liquids present in the operation theatre. Barrier operating clothing can play an important part in reducing infection spread in the operation theatres. ${ }^{2,3}$

The potential of surgical gowns to prevent from contamination depends on the physical conditions i.e. their physical properties. Researchers found that there should be some specific characteristics in surgical gowns have capacity to resist against scratch, tear, flame, liquid strike, bacterial strike and any kind of discharge. Modern technology has successfully incorporated just some of these properties into surgical gowns (Disposable or Reusable). Therefore some characteristics have to be compromised upon to attain the more desirable ones but all is not done. Some properties did not incline to get along with each other whereas some of the features did so. ${ }^{13}$

Although it is known that laundering affects the shield properties of fabric material,. ${ }^{15}$ Not many studies have published on barrier efficacy of surgical gowns..$^{20,21}$ Studies have been conducted in the operation theatre rooms to assess the barrier efficiency to bacterial infection spread of different operating gowns. ${ }^{14,20,21}$

Surgical gowns being used in hospitals are mainly of two types; disposable and reusable surgical gowns. Surgical gowns provide the resistance not only against environment but also microorganisms and impact forces etc..$^{9,10,16}$
The current study is being conducted to study the current scenario of surface wetting of surgical gowns in private and Govt. hospitals of Lahore.

\section{MATERIALS \& METHODS}

An experimental study was designed to evaluate the surface wetting of surgical gowns currently being used in various hospitals of Lahore. Fifteen hospitals were selected for study (both govt. and private sector hospitals). The sample was selected randomly and categorized into three groups $A, B, \& C$ on the bases of socio economic condition of the patients. The sample was tested before and after laundering and sterilization. Each sample was tested after completing five cycles of laundering and sterilization.

Determination of Resistance to Surface Wetting (Spray Test) of Fabrics:

All the samples of surgical gowns were subjected to determination of resistance to surface wetting (spray test) of fabrics following. ${ }^{8}$ For this purpose, at least three test specimens were taken from each laboratory sample, $180 \mathrm{~mm}$ square, from different places in the fabric in order to represent the material as fully as possible. No specimen was taken from places with creases or fold marks. The test specimens were conditioned for $24 \mathrm{~h}$ in the standard atmosphere. ${ }^{11}$ After conditioning, each test specimen was mounted securely on the specimen holder and placed it with the face of the fabric uppermost on the hoop support. The specimen was oriented so that the warp direction is parallel to the flow of the water down the specimen. $250 \mathrm{ml}$ of water was poured into the funnel quickly, but steadily so that the spraying was continuous once it had commenced. Immediately the spray was ceased, removed the holder with its specimen and tapped smartly twice against a solid object (on diametrically opposite points of the frame). During this operation, the plane of the fabric was almost horizontal, with the fabric face down. After tapping, with the specimen still on the holder, the specimen was assigned a rating in the following descriptive scale or in the photographic scale which best describes the observed degree of wetting. No attempt was made to assign intermediate ratings. ${ }^{8}$ 


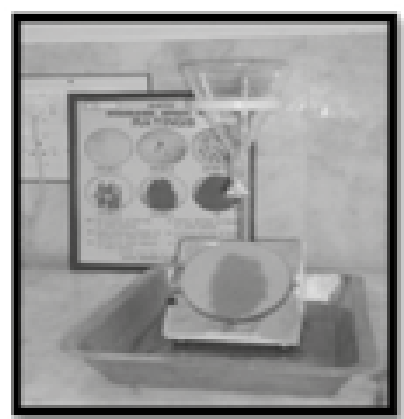

B-1

Figure-1. Resistance to Surface Wetting (ISO Spray Test)

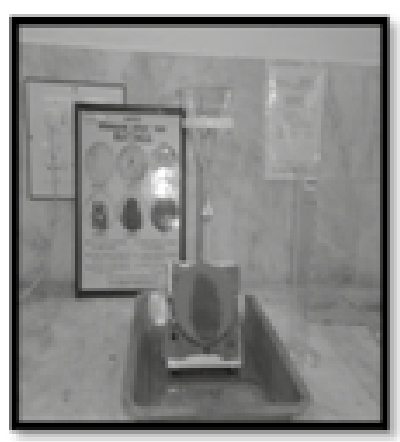

C-4

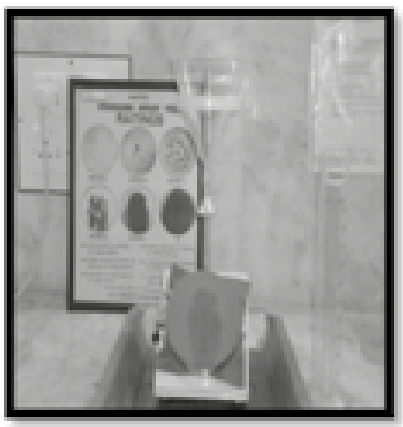

B-3
Figure-2. Resistance to Surface Wetting (ISO Spray Test)

\section{RATING OF ISO SPRAY TEST}

\begin{tabular}{|l|c|}
\hline \multicolumn{1}{|c|}{ Condition } & Rating \\
\hline Wetting of the whole of the sprayed surface. & 01 \\
\hline $\begin{array}{l}\text { Wetting of the half of the sprayed surface. } \\
\text { This usually occurs through the merging of } \\
\text { small discrete wetting areas }\end{array}$ & 02 \\
\hline $\begin{array}{l}\text { Wetting of the sprayed surface only at small } \\
\text { discrete areas. }\end{array}$ & 03 \\
\hline $\begin{array}{l}\text { No wetting of, but adherence of small drops } \\
\text { to, the sprayed surface. }\end{array}$ & 04 \\
\hline $\begin{array}{l}\text { No wetting of, and no adherence of small } \\
\text { drops to, the sprayed surface. }\end{array}$ & 05 \\
\hline
\end{tabular}

\section{RESULTS}

Fifteen samples were mounted according to the test method and experiments were performed. Resistance to Surface Wetting (Spray Test).

Resistance to surface wetting is an important parameter for any surgical gown to be functional and effective. The material used the weight of the fabric, the surface treatment, the number of

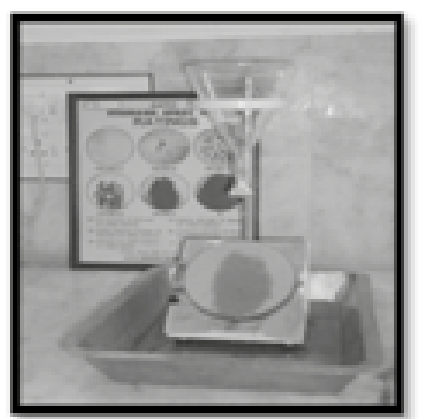

B-2

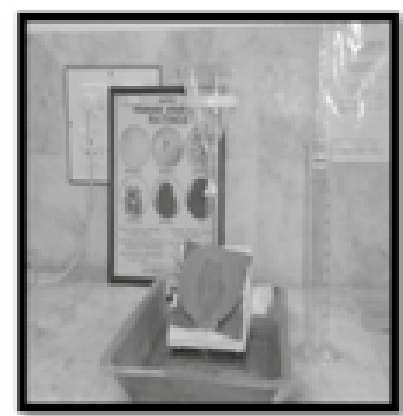

C-1
Figure-2. Resistance to Surface Wetting (ISO Spray Test)
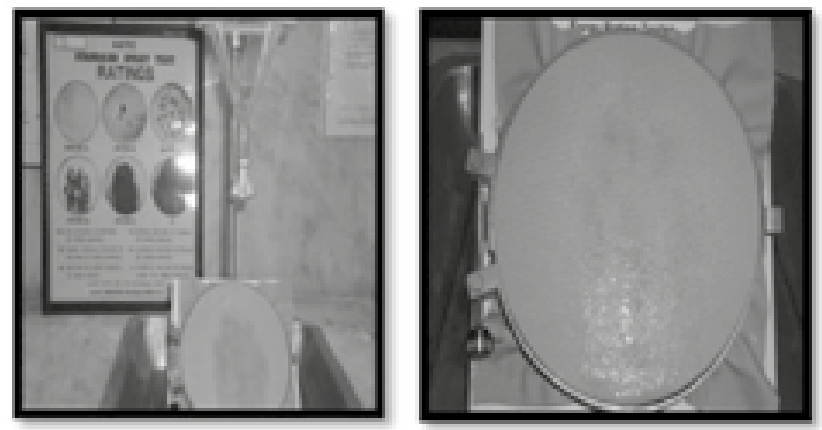

A-2

Figure-4. Resistance to Surface Wetting (ISO Spray Test)

laundering cycles and other factors affect the resistance to surface wetting and the barrier efficacy. The gowns, which were subjected for the spray test were tested before and after laundering and sterilization. They did not show much resistance to fluid penetration either in initial phase of analysis or in the end of the laundering cycle. All gowns were equally poor in resistance to surface wetting. ISO standard - 05 (Table-I).

The above table describes the average statistics for resistance to surface wetting (Spray Test) of fabrics at various laundering intervals. In Group $A$, these mean numbers after spray test were reported as $0.60 \pm 0.89$ for new gown (before laundering), $0.20 \pm 0.44$ at $5^{\text {th }}$ Laundering, $0.20 \pm 0.44$ at $10^{\text {th }}$ Laundering and $0.00 \pm 0.00$ at $15^{\text {th }}$ and $20^{\text {th }}$ Laundering. However, in both Groups i.e. B and C, the average mean number for resistance to surface wetting was $0.20 \pm 0.44$ at 0 Laundering (new gown) and 0.00 at all other laundering from $5^{\text {th }}$ to $20^{\text {th }}$ laundering intervals. It 
clearly shows that resistance of fabric to surface wetting diminished between 1-5 laundries in almost all study groups. Statistically, the average resistance of fabric to surface wetting was same in all study groups. i.e. ( $p$-value=0.06).

\begin{tabular}{|c|c|c|c|c|}
\hline & Groups & $\mathbf{N}$ & Mean & SD \\
\hline \multirow{3}{*}{$\begin{array}{l}\text { Resistance to Surface Wetting (Spray Test) of Fabrics } \\
\text { (New Gown before washing) }\end{array}$} & Group-A & 5 & 0.60 & 0.89 \\
\hline & Group-B & 5 & 0.20 & 0.44 \\
\hline & Group-C & 5 & 0.20 & 0.44 \\
\hline \multicolumn{2}{|l|}{ Total } & 15 & 0.33 & 0.61 \\
\hline \multirow{3}{*}{$\begin{array}{l}\text { Resistance to Surface Wetting (Spray Test) of Fabrics } \\
\text { (After 05-laundering) }\end{array}$} & Group-A & 5 & 0.20 & 0.44 \\
\hline & Group-B & 5 & 0.00 & 0.00 \\
\hline & Group-C & 5 & 0.00 & 0.00 \\
\hline \multicolumn{2}{|l|}{ Total } & 15 & 0.06 & 0.25 \\
\hline \multirow{3}{*}{$\begin{array}{l}\text { Resistance to Surface Wetting (Spray Test) of Fabrics } \\
\text { (After 10-laundering) }\end{array}$} & Group-A & 5 & 0.20 & 0.44 \\
\hline & Group-B & 5 & 0.00 & 0.00 \\
\hline & Group-C & 5 & 0.00 & 0.00 \\
\hline \multicolumn{2}{|l|}{ Total } & 15 & 0.06 & 0.25 \\
\hline \multirow{3}{*}{$\begin{array}{l}\text { Resistance to Surface Wetting (Spray Test) of Fabrics } \\
\text { (15-laundering) }\end{array}$} & Group-A & 5 & 0.00 & 0.00 \\
\hline & Group-B & 5 & 0.00 & 0.00 \\
\hline & Group-C & 5 & 0.00 & 0.00 \\
\hline \multicolumn{2}{|l|}{ Total } & 15 & 0.00 & 0.00 \\
\hline \multirow{3}{*}{$\begin{array}{l}\text { Resistance to Surface Wetting (Spray Test) of Fabrics } \\
\text { (after 20-laundering) }\end{array}$} & Group-A & 5 & 0.00 & 0.00 \\
\hline & Group-B & 5 & 0.00 & 0.00 \\
\hline & Group-C & 5 & 0.00 & 0.00 \\
\hline \multicolumn{2}{|l|}{ Total } & 15 & 0.00 & 0.00 \\
\hline
\end{tabular}

Table-I. Descriptive Statistics for Resistance to surface Wetting (Spray Test) of Fabric at different Intervals Factor $(p$-value $)=0.056$ (Insignificant: $p$-value $>0.05$ )

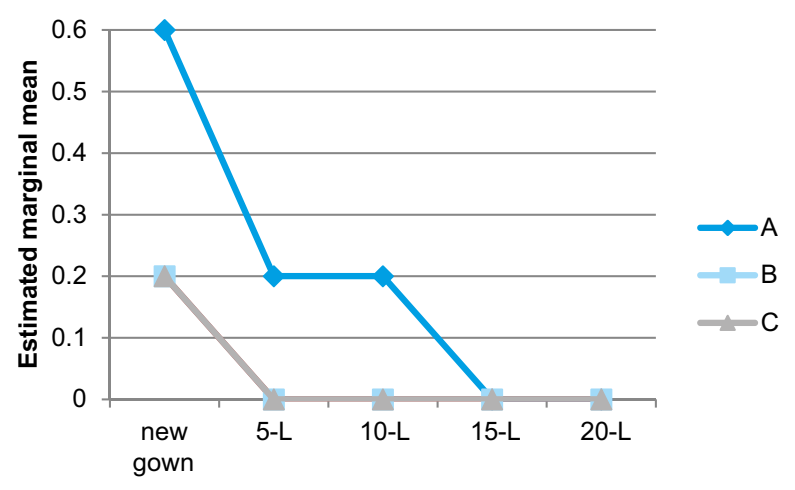

Factor

\section{Factor*Group ( $p$-value) $=0.423$ (Insignificant:} p-value $>0.05$

Figure-5. Resistance to Surface Wetting (Spray Test) of Fabrics at different Laundry Intervals

According to the above graph figure 04 the resistance of fabric to surface wetting (spray test) was absolutely same in Group B and C. However, in Group A, the values were slightly greater than other two groups from new gown to $10^{\text {th }}$ laundering intervals and became null in further laundering, similar to group A and B. The resistance to surface wetting nullified in almost all groups after $5^{\text {th }}$ laundry and no statistical difference was observed in resistance of fabric in all groups i.e. ( $p$-value $=0.423)$.

\section{DISCUSSION}

The liquid/water penetration on the fabric surface was increased over repeated laundering ${ }^{5}$ intervals and this increase in penetration was statistically same in all three groups.

i.e. $(p$-value $=0.06)$. Overall a increasing trend was observed for surface wetting in all 3 groups of hospitals from 0 to $20^{\text {th }}$ laundering. However, in both Groups i.e. B and C, the average mean number for resistance to surface wetting was $0.20 \pm 0.44$ at 0 Laundering (new gown) and 0.00 at all other laundering from $5^{\text {th }}$ to $20^{\text {th }}$ laundering intervals. The increasing trend of liquid penetration indicates that fabric is losing its barrier/blockade quality and becoming weaker because during 
wear and laundering abrasion removes the fur/lint from the surface layer of fabric and cause it weak and in some situations less dense. ${ }^{6 \& 7}$ The cause is repeated washing, use of strong detergents/ soaps/ and excessive use of bleaches and steam (sterilization). ${ }^{18}$

The gowns, which were subjected for the spray test, did not show much resistance to fluid penetration either in initial phase of analysis or in the end of the laundering cycle. This might be due to the reason that there were no finishes applied on the fabric surface. The gowns were not given any water repellent finish at all. All gowns were equally poor in resistance to surface wetting. This is an undesirable quality for surgical gowns. Cotton is hydrophilic in nature, which allows for seepage and penetrations when surgical gowns are splashed with water/simulated body fluids. ${ }^{22}$ This gives reason to all cotton made gowns to wet readily. Mostly cotton made gowns had an irregular (lint) surface. The irregular (lint) surface prevents the liquid from moving off the fabric, thus helping liquid penetration in the fabric. Previous researches have shown that wet fabrics are poorer barriers than are dry fabrics. ${ }^{4}$ According to Leonas study in 1998 repellency contributes to gown performance. Higher liquid repellency ratings generally relate with higher barrier properties.

\section{CONCLUSION}

The factor under consideration in this study was the resistance of existing surgical gown fabric to surface wetting. The surgical gowns were collected from fifteen different hospitals under study. These surgical gowns were subjected to ISO-Spray test to check the liquid barrier function of the fabric. The results proved that the fabric used for the surgical gowns was not up to the mark and did not show any resistance against fluid. The surgical gowns fabric disqualified the ISO-Spray test. Gowns rating were then checked against international standards. These gowns did not match any international standard or parameter either. After repeated launderings most of the gowns were torn and became discolored. Among three groups under study group A showed highest ratings in ISO-Spray test where as for weft yarns group $c$ failed the test.

Copyright@ 30 June, 2017.

\section{REFERENCES}

1. ASTM. (2012, January 04). Recommended Standards of Practice for Surgical Drapes.

2. Batra, S. (1992). Medical and Surgical Disposibles Protect Healthcare Workers and Patient. In 3rd (Ed.), The Nonwoven Fabrics Handbook (pp. 19-22). India.

3. Behera, B.K.,Arora, H. (2009). Surgical Gown: A Critical Review. J Indus Textiles, 38-205.

4. Beck, W.C., Collete, T.S. (1952). False faith in the surgeon's gown and surgical drape. Am J Surg, 125-126.

5. Coughlin, M. (1999). Effect of laundering on the barrier properties of reusable surgical gown fabrics. AORN Journal, 73-82.

6. DiGiiacomo, M.C., Swan, P.G., Ritota, K.C. and Odom, J.W. (1992). Contamination in the operating room: Use of reusable verses disposable clothing. The American Surgeon, 654-656.

7. EN13795. (2007). Standard for Surgical Drapes, used as Medical Devices. Retrieve from; EN13795. (2007). EU Standard for Surgical Drapes, Gowns and Clean Air Suits, used as Medical Devices. Online available from: http://www.pregis.com/LinkClick.aspx? link=Sengewalddatas\%2Fagbs $\% 2$ FEN $+13795+$ GB . pdf\&tabid $=519 \& \mathrm{mid}=1686$.

8. EN 24920. (1992). Determination of Resistance to Surface Wetting (Spray Test) of Fabrics.

9. Gershon,R. and Vlahov,D. (1992). Assessing and reducing HIV risk to the critical care nurse. Critical Care Nursing Currents 3.

10. Gershon,R. and Zirkin,B. (1995). Behavioral factors in safety training in laboratory safety. Washington, DC: AMS Press.390-395.

11. ISO139. (2012, Nov. 3rd). Textiles-standard atmosphere for conditioning and testing. Retrieved from http://www.iso.org/iso/iso_catalogue/catalogue_tc/catalogue_detail.htm?csnumber $=35179$

12. Kishwar,F.,Kalsoom,S.,Khan,F.,Alam,S. (2011). Surgical apparels: comparison of some physical parameters. Professional Med J.,

13. Kitson, R.P., Gilbert, R.L. and Israel, J. (1980). Composite non-woven fabric comprising adjacent microfine fibers in layers. AORN J, 520-530. 
14. Leonas, K.K. and Jinkins, R.S. (1997). The relationship of selected fabric characteristics and the barrier effectiveness of surgical gown fabric. Am J Infect Control, 16-23.

15. Leonas, K. (1985). Apparel fabrics as barriers to pesticide penetration. University of Tennessee.

16. Manz, E.A. \& Edgar, B.L. (1998). Examining draping practices for cost-effectiveness. Surg Serv Manag, 41-47.

17. Rutala, W.A. and Weber, D.J. (2001). A review of single use and reusable gowns and drapes in health care. Infect Control Hosp Epidemiol, 248-257.

18. Rutala, W.A. and Weber, J.J. (2001). Review of disposable \& reusable surgical gowns and drapes in health care. Infect Control Hosp Epidemiol, 248-257.
19. Stoessel, K.B. and Truscott, W. (2008). Surgical gowns: selection and best practices for protection. Retrieved from www.pfiedler.com/ce/1172/1172.pdf.

20. Shadduck, P.P., Tyler D.S., Lyerly H.K., Sebastian M.W., Farminto C., Fitzpatrick K.T., et al. (1994). Commercially available surgical gowns donot prevent penetration by HIV-1.

21. Smith, J.W. and Nichols, R.L. (1991). Barrier efficiency of surgical gowns: Are we really protected from our patients' pathogens? Arch Surg, 756-763.

22. Vigo, T.L. (1978). Modified cellulosics. New York: Academic Press.

23. Woodhead, K., Taylor, E.W., Bannister, G., Chesworth, T., Hoffman, P. and Humphreys, H. . (2002). Behaviours and rituals in the operating therater. Journal of Hospital Infection, 241-255.

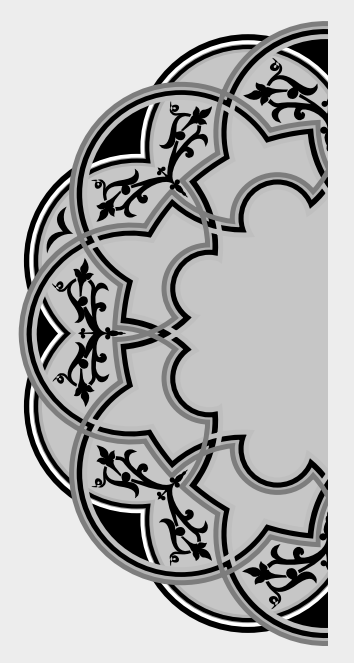

\title{
"Listen without defending; speak without offending."
}

\author{
Unknown
}

\section{AUTHORSHIP AND CONTRIBUTION DECLARATION}

\begin{tabular}{c|r} 
Sr. \# & Author-s Full Name \\
\hline 1 & Farzana Kishwar \\
\hline
\end{tabular}

2 Fatima Ali
Contribution to the paper

Introduction, Research

Methodology Experimentation

Results Summary \& Conclusion

Discussion Statistical Analysis

References Editing \& Formatting
Author $=\mathbf{s}$ Signature

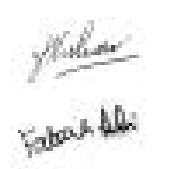

